\title{
The role of acoustic signals for species recognition in redfronted lemurs (Eulemur rufifrons)
}

\author{
Hanitriniaina Rakotonirina ${ }^{1 *}$, Peter M. Kappeler ${ }^{1,2}$ and Claudia Fichtel ${ }^{1}$
}

\begin{abstract}
Background: Signals are essential for communication and play a fundamental role in the evolution and diversification of species. Olfactory, visual and acoustic species-specific signals have been shown to function for species recognition in non-human primates, but the relative contributions of selection for species recognition driven by sexual selection, natural selection, or genetic drift for the diversification of these signals remain largely unexplored. This study investigates the importance of acoustic signals for species recognition in redfronted lemurs (Eulemur rufifrons). We conducted playback experiments in both major populations of this species separated by several hundred kilometers: Kirindy Forest in the west and Ranomafana National Park in the east of Madagascar. The playback stimuli were composed of speciesspecific loud calls of E. rufifrons, three closely related species (E. albifrons, E. fulvus and E. rufus) and one genetically more distant species (E. rubriventer) that occurs in sympatry with eastern redfronted lemurs. We tested the ability of redfronted lemurs to discriminate conspecific from heterospecific loud calls by measuring the time spent looking towards the speaker after presentation of each loud call. We also tested the difference between female and male responses because loud calls may play a role in mate choice and the avoidance of heterospecific mating.

Results: Redfronted lemurs in Kirindy Forest did not discriminate their own loud calls from those of E. albifrons, E. fulvus and E. rufus, but they discriminated loud calls of E. rubriventer from their own. The Ranomafana population was tested only with three playback stimuli (E. rufifrons, E. albifrons, E. rubriventer) and did not discriminate between their own loud calls and those of E. albifrons and E. rubriventer. The response of females and males to playbacks did not differ in both populations. However, subjects in Ranomafana National Park responded more strongly to playback stimuli from E. rubriventer than subjects in Kirindy Forest.

Conclusions: We conclude that in both populations individuals were not able to discriminate between loud calls of closely related species living in allopatry and that responses to more distantly related congeners are likely to be modulated by experience. Subjects in Ranomafana paid more attention to loud calls of syntopic E. rubriventer in comparison to the Kirindy subjects, suggesting that experience is important in facilitating discrimination. Because acoustic and genetic distances among eulemurs are correlated, diversification in their acoustic signals might be the result of genetic drift.
\end{abstract}

Keywords: Eulemur rufifrons, Species recognition, Acoustic signals, Mate choice, Genetic drift

\footnotetext{
* Correspondence: hrakotonirina@dpz.eu

'Behavioral Ecology \& Sociobiology Unit, German Primate Center, Göttingen,

Germany

Full list of author information is available at the end of the article
} 


\section{Background}

Signals are not only essential for conspecific communication, but also play an important role in the evolution and diversification of species [1-3]. Species-specific signals may evolve in response to different evolutionary pressures. First, such signals may represent the result of sexual selection if they function as a premating isolation mechanism [4], requiring the ability for species recognition in heterospecific receivers [5-9]. Based on the ability of an individual to discriminate between signals from its own and other species, species recognition is used in many different taxa to avoid costly interbreeding. This ability has been demonstrated in several taxa, such as bats using olfactory signals [10], fish using olfactory or visual signals [11, 12] and frogs, birds and mammals using acoustic signals [6, 13-15].

Second, species-specific signals can also be the result of natural selection through adaptations to local habitat conditions. For example, frogs (Amolops tormotus) living close to noisy streams shifted the frequency of their calls in the ultra-sound range to avoid masking of background noise of the stream [16]. In little greenbul (Andropadus virens) occurring in two different forest types (rainforest or ecotone forest), habitat-dependent selection has also been suggested to cause divergence of acoustic traits because songs of rainforest populations differ in spectral and temporal characteristics compared to those in the ecotone forest [17]. Finally, signal diversification may also be driven by cultural or genetic drift, where stochastic processes generate species-specific signals in the absence of selection [18]. For example, in greenish warblers (Phylloscopus trochiloides) and Neotropical singing mice (Scotinomys teguina, S. xerampelinus), diversification in songs was shown to be correlated with both geographic distance and genetic divergence, suggesting that differentiation in this signal were largely shaped by genetic drift $[19,20]$. Although the ability to use signals for species recognition is widespread, the relative contributions of selection for species recognition driven by sexual selection, natural selection, or genetic drift for the diversification of species signals remain poorly understood.

Primates are an interesting taxon for studies of species recognition because they often occur in sympatry with other species, they inhabit a range of tropical habitats, and they exhibit social communication, relying on olfactory, visual and acoustic signals. Sexual selection has been suggested to have driven diversification of primate olfactory signals [21, 22], and species recognition based on olfactory cues has been demonstrated in true lemurs (Eulemur sp. [23]), bushbabies (Galago sp. [24]) and capuchin monkeys (Cebus sp. [25]). Interspecific variation in visual signals has also been suggested to function in species recognition among primates [26-28]. For example, in both New World monkeys (platyrrhines) and Old World monkeys (catarrhines), facial color complexity is positively related to the number of sympatric congeners [29, 30]. However, the evolution of facial pigmentation and hair length in platyrrhines was linked to ecological factors since these traits are strongly related to the geographical distribution of species [29].

Acoustic signals have also been suggested to represent a useful tool for species delimitation in several primate species, including lion tamarins (Leontopithecus rosalia, $L$. chrysopygus and L. chrysomelas [31]), crested gibbons (Nomascus gabriellae and N. leucogenys siki [32]) and lemurs (Lemuridae [33]). Even in closely related species, such as gibbons (Nomascus nasutus, N. concolor, N. leucogenys, N. siki, N. annamensis and N. gabriellae [34]), langurs (Presbytis thomasi, P.potenziani siberu, P.comata comata and all four subspecies of $P$. melalophos ( $P . \mathrm{m}$. melalophos, P. m. mitrata, P.m.bicolor and P.m.sumatrana) [35]), Decken's and crowned sifakas (Propithecus deckenii and P. coronatus [36]), or in black lemurs (Eulemur macaco and E. flavifrons [37]), calls are characterized by species-specific acoustic structure. However, whether these differences between acoustic signals evolved in the context of species recognition and are used to discriminate between conspecifics and heterospecifics by the animals remains unknown. Moreover, whether call divergence has been driven by habitat adaptations, as in catarrhines [38], or is the result of stochastic processes, as in gibbons [34], or of sexual selection, as in orangutans (Pongo sp. [39]), is often also unknown.

Specific tests involving playback experiments to demonstrate that primates are able to discriminate heterospecific from conspecific calls have only rarely been conducted (e.g. in tarsiers, Tarsius spp. [40]; macaques, (Macaca tonkeana, M. maurus, $M$. hecki and $M$. nigrescens) [41]; gibbons, Hylobates spp. [15, 42] and mouse lemurs, Microcebus ssp.: [43]) and yielded variable results. For example, Nietsch and Kopp [40] found that Tarsius spectrum discriminated vocalizations of conspecifics and heterospecifics (Diane's and Tongian tarsiers). Mitani [42] showed that agile gibbons (Hylobates agilis) responded similarly to conspecific songs from the local and allopatric populations but differentiated between those and allopatric heterospecific songs $(H$. muelleri). Finally, gray mouse lemurs (Microcebus murinus), which occur in sympatry with golden-brown mouse lemurs (M. ravelobensis) but in allopatry with Goodman's mouse lemurs ( $M$. lehilahytsara) responded stronger to conspecific than to heterospecific advertisement calls (essential in the context of reproduction) and, interestingly, stronger to calls of the allopatric than the sympatric species [43]. This result suggests that the spatial cohesiveness of species in sympatry led to species-specific divergence of acoustic signals to avoid costly hybridization [43]. Thus, primates are able to discriminate between conspecific and heterospecific calls, irrespective of whether they occur in 
sympatry or allopatry (indicating different diversification mechanisms of acoustic signals in different genera).

In this study, we investigated the ability of redfronted lemurs (Eulemur rufifrons) to discriminate between loud calls of allopatric and sympatric congeners. The endemic Malagasy genus Eulemur consists of 12 species occupying all major primary habitats in Madagascar. Seven species of the genus, formerly classified as the "Eulemur fulvus group" (E. albifrons, E. cinereiceps, E. collaris, E. fulvus, E. rufifrons, E. rufus, and E. sanfordi) are closely related and probably diverged only in the last million years [44]. Geographically, they are distributed in allopatric populations and the other species of the genus Eulemur (E. coronatus, E. flavifrons, E. macaco, E. mongoz, and E. rubriventer) are distributed in sympatry with one of the "Eulemur fulvus group" taxa [45]. Loud calls or "croaks" in eulemurs are long and noisy vocalizations that are used during intergroup encounters and as alarm or group cohesion calls [46, 47]. The acoustic structure of Eulemur loud calls shows considerable variation, with subtle differences between loud calls of species belonging to the "Eulemur fulvus group", but pronounced acoustic differences between loud calls of members of the "Eulemur fulvus group" and the other five members of the genus [44]. Thus, diversification of acoustic signals of Eulemur species occurring in allopatry is not pronounced, whereas sympatric species differ, suggesting that the need for reliable species recognition may have favored acoustic diversification.

Accordingly, we predicted that in response to playback experiments, eulemurs do not discriminate (operationalized as time spent looking towards the speaker) between their own loud calls and those of allopatric species, but between their own and loud calls of sympatric congeners. If, however, diversification of acoustic signals is the result of genetic drift, we predicted that eulemurs do not discriminate between loud calls of genetically closely related congeners, but between loud calls of more distantly related congeners. Finally, as heterospecific mating is more costly for females because they invest more in reproduction than males [48, 49], females should respond stronger to these loud calls than males.

Redfronted lemurs are an interesting model species to evaluate the relative importance of different evolutionary pressures in shaping species-specific acoustic signals because this species has a disjunct distribution, with subpopulations occurring in western dry deciduous forests and eastern mountain rain forests (Fig. 4). Whereas $E$. rufifrons populations in the east are sympatric with a congeneric species (E. rubriventer), western populations have no sympatric congener. In addition, $E$. rufifrons and $E$. rubriventer produce loud calls during interspecific group encounters (Rakotonirina pers. obs). The acoustic differences between $E$. rubriventer and E. rufifrons are much more pronounced than between more closely related species [44]. A previous study indicated no acoustic difference between eastern and western populations, suggesting that there might be no habitat effect on acoustic signals of the two populations of $E$. rufifrons [44]. Since western $E$. rufifrons do not occur in sympatry with $E$. rubriventer but eastern populations do, we predicted different responses to the respective loud calls in each population. Accordingly, western $E$. rufifrons should not discriminate between their own calls and those of E. rubriventer, whereas eastern redfronted lemurs should do so.

\section{Results}

Responses of redfronted lemurs at Kirindy Forest (KF) The percentage of time spent looking towards the speaker during the first minute following the onset of a playback differed significantly among stimuli (Table 1, LMM, $\mathrm{X}^{2}=16.64, p=0.005$ ). Specifically, E. rufifrons spent less time looking towards the speaker after the presentation of loud calls of the genetically more distantly related E. rubriventer (Fig. 1a). There was no sex difference in the percentage of time spent looking towards the speaker after presentation of the different playback stimuli (Table 1). However, the percentage of time spent looking towards the speaker was significantly influenced by the genetic distance between the species (Table 1, LMM, $\mathrm{X}^{2}=16.15, p<0.001$ ).

\section{Responses of redfronted lemurs in Ranomafana National Park (RNP)}

Eulemur rufifrons at RNP did not differ in the average percentage of time spent looking towards the speaker during the first minute following the onset of a playback between the three different playback stimuli of $E$. albifrons, E. rubriventer and E. rufifrons (Fig. 1b, Table 1, LMM, $\mathrm{X}=3.49, p=0.321$ ). There was also no sex difference in time spent looking towards the speaker after presentation of the different playback stimuli (Table 1). The percentage of time spent looking towards the speaker was not influenced by the genetic distance of the two species (Table 1, LMM, $\mathrm{X}^{2}=0.46, p=0.79$ ).

\section{Comparison between redfronted lemurs at KF and RNP}

The comparison of looking responses between redfronted lemurs from both populations revealed no significant differences in time spent looking towards the speaker after the presentation of their own species loud calls (Mann Whitney $U$ test, $p=0.993$ ) and loud calls of $E$. albifrons (Mann Whitney $U$ test, $p=0.132$ ). However, redfronted lemurs at RNP spent significantly more time looking towards the speaker after presentation of the sympatrically occurring $E$. rubriventer than redfronted lemurs at KF, which do not occur sympatrically with $E$. rubriventer (Mann Whitney $U$ test, $p=0.026$, Fig. 2a, b and c). 
Table 1 Parameter estimates for the Linear Mixed Models (LMM) on the influence of the different playback stimuli and the genetic distance between species on the percentage of time spent looking towards the speaker for redfronted lemurs tested at Kirindy (a, b) and at Ranomafana (c, d)

\begin{tabular}{|c|c|c|c|c|c|c|c|}
\hline & Model & Response variable & Random factors & Fixed factors & Estimate & SE & $P$-value \\
\hline \multirow[t]{6}{*}{ a } & \multirow[t]{6}{*}{ LMM } & \multirow[t]{6}{*}{ Percentage of time spent looking towards the speaker } & \multirow[t]{6}{*}{ individual identity } & intercept & 0.56 & 0.08 & $<0.001$ \\
\hline & & & & E. rufus & 0.02 & 0.11 & 0.81 \\
\hline & & & & E. albifrons & -0.02 & 0.11 & 0.85 \\
\hline & & & & E. fulvus & 0.01 & 0.11 & 0.91 \\
\hline & & & & E. rubriventer & -0.33 & 0.11 & 0.003 \\
\hline & & & & sex & -0.07 & 0.68 & 0.28 \\
\hline \multirow[t]{3}{*}{$b$} & \multirow[t]{3}{*}{ LMM } & \multirow[t]{3}{*}{ Percentage of time spent looking towards the speaker } & \multirow[t]{3}{*}{ individual identity } & intercept & 0.60 & 0.05 & $<0.001$ \\
\hline & & & & genetic distance & -0.08 & 0.02 & $<0.001$ \\
\hline & & & & sex & -0.07 & 0.07 & 0.29 \\
\hline \multirow[t]{4}{*}{ c } & \multirow[t]{4}{*}{ LMM } & \multirow[t]{4}{*}{ Percentage of time spent looking towards the speaker } & \multirow[t]{4}{*}{ individual identity } & intercept & 0.28 & 0.1 & $<0.001$ \\
\hline & & & & E. rubriventer & 0.12 & 0.11 & 0.09 \\
\hline & & & & E. albifrons & 0.19 & 0.11 & 0.49 \\
\hline & & & & sex & 0.09 & 0.11 & 0.42 \\
\hline \multirow[t]{3}{*}{$d$} & \multirow[t]{3}{*}{ LMM } & \multirow[t]{3}{*}{ Percentage of time spent looking towards the speaker } & \multirow[t]{3}{*}{ individual identity } & intercept & 0.39 & 0.09 & $<0.001$ \\
\hline & & & & genetic distance & -0.001 & 0.02 & 0.97 \\
\hline & & & & sex & 0.07 & 0.11 & 0.52 \\
\hline
\end{tabular}

\section{Genetic and acoustic distances}

The genetic distance of the five species correlated positively with their acoustic distance (Spearman rank: rho $=0.98, p=0.005$; Fig. 3).

\section{Discussion}

This study investigated the ability of Eulemur rufifrons to discriminate between conspecific and heterospecific loud calls. In KF, E. rufifrons did not discriminate between loud calls of closely related E. albifrons, E. fulvus and E. rufus.
However, they discriminated between their own loud calls and those of E. rubriventer, as demonstrated by the shorter time spent looking towards the speaker. In RNP, E. rufifrons also did not discriminate between their own loud calls and those of the closely related $E$. albifrons but also not between their own calls and those of the more distantly related E. rubriventer. However, redfronted lemurs at RNP spent on average more time looking towards the speaker after presentations of E. rubriventer loud calls than did E. rufifrons in KF.

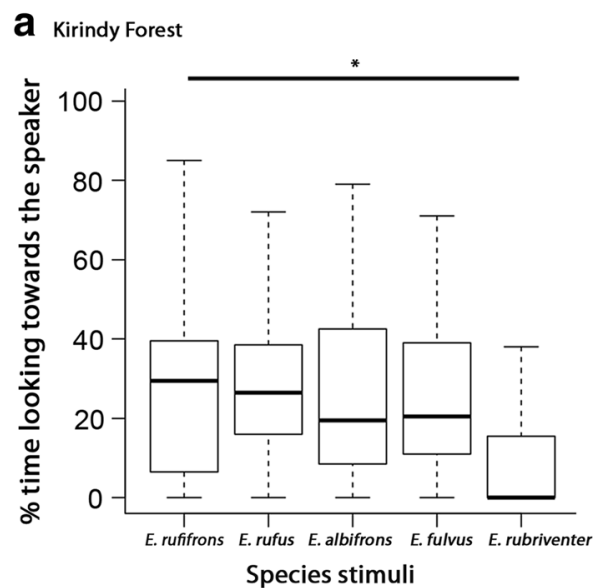

b Ranomafana National Park

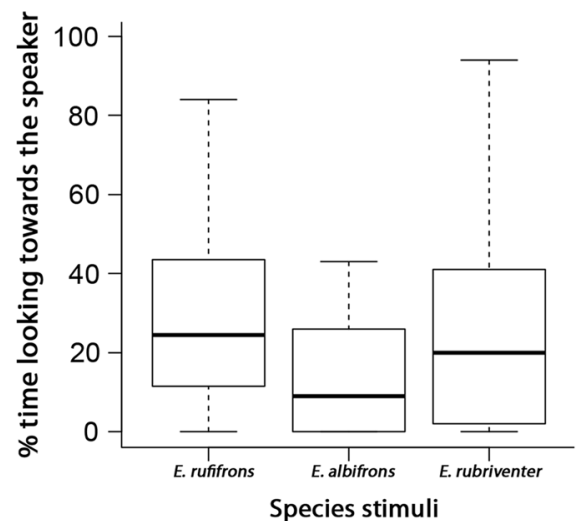

Fig. 1 a, b Boxplot of the percentage of time spent looking towards the speaker of Eulemur rufifrons in (a) Kirindy Forest and (b) in Ranomafana National Park in response to playbacks of loud calls from different congeneric species. Depicted are the median (black bars), interquartile range (boxes) and ranges (whiskers) 

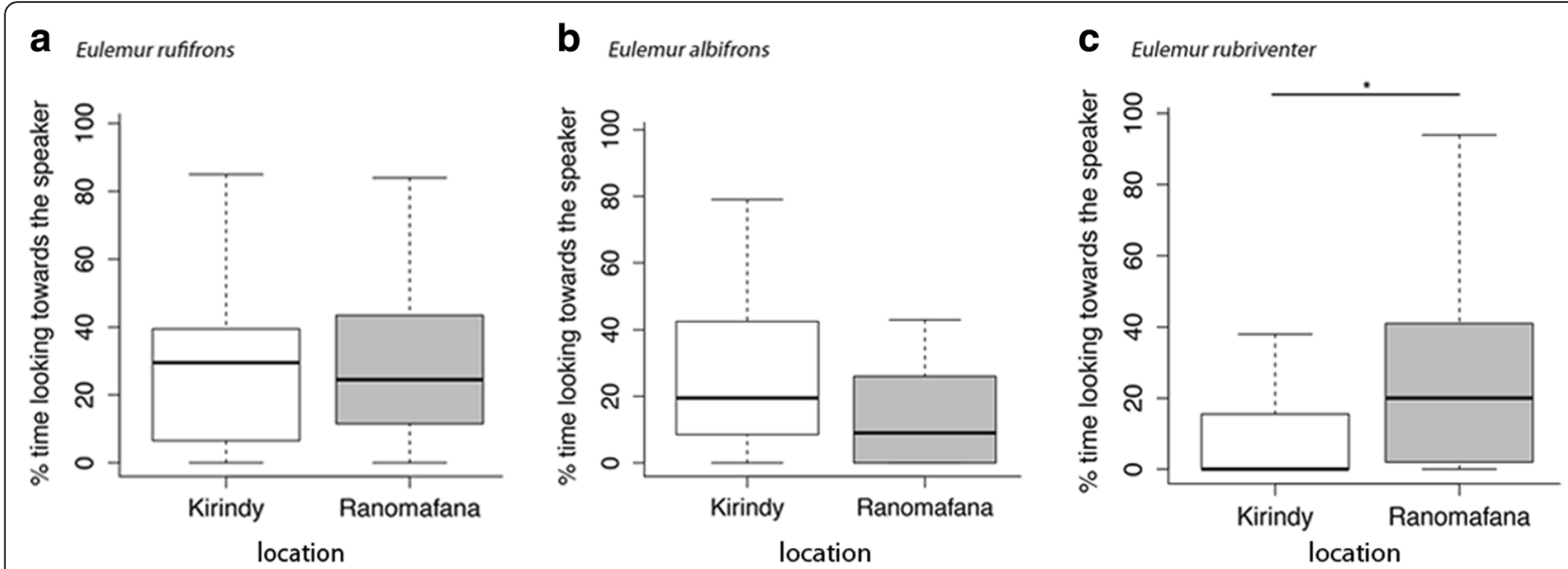

Fig. $\mathbf{2}$ a, b, c Boxplot of time spent looking towards the speaker after presentation of playbacks of $\mathbf{a}$ E. albifrons, $\mathbf{b} E$. rufifrons and $\mathbf{c} E$. rubriventer in KF (white) and RNP (grey). Represented are the median (black bars), interquartile range (boxes) and range (whiskers)

\section{Species recognition and sexual selection}

Vocalizations in numerous species of animals, including frogs, insects, birds and primates, are considered to be reliable source for the taxonomic delineation of subspecies or species $[4,20,32,50]$. However, taxonomic decisions based on difference in vocalizations rarely consider the behavioral reactions of animals to acoustic cues and whether differences measured in vocalizations between subspecies and species are meaningful in terms of reproductive isolation for the taxa in question. Our study showed that differences among loud calls measured in previous studies between closely related eulemur species [44] are apparently meaningless for the animals in terms

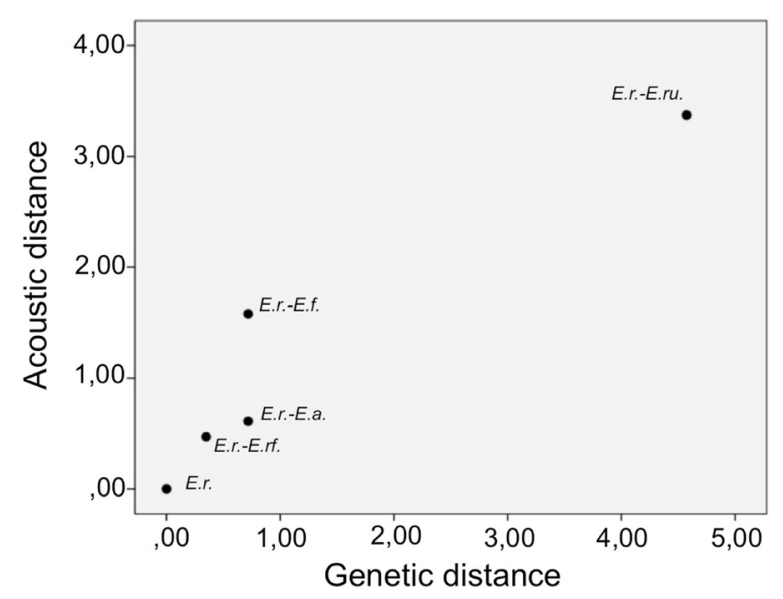

Fig. 3 Acoustic distance vs. genetic distance between E. rufifrons and the Eulemur species used as stimuli. Each dot represents acoustic distance vs. genetic distance of one species pair. E.r.: E. rufifrons, E.r.-E.rf. E. rufifrons - E. rufus, E.r-E.a.: E. rufifrons - E. albifrons, E.r.-E.f: E. rufifrons E. fulvus, E.r.-E.ru.: E. rufifrons - E. rubriventer of a potential reproductive barrier. We therefore suggest that taxonomic studies should investigate several traits and consider also the behavioral responses of the animals under study to traits supposedly involved in reproductive isolation.

The responses of females and males during all playback experiments did not differ from each other in time spent looking towards the speaker. Because females are known to invest more into reproduction than males, and heterospecific mating might be more costly for them $[48,51]$, we predicted that they should pay more attention to the loud calls and show stronger responses than males. In species where loud calls are also used in the mating context, such as in gibbons [34] or langurs [35], sexual selection might have driven the diversification of calls. However, differences seen between loud calls of $E$. rufifrons and closely related species are obviously not strong enough to contribute to reproductive isolation at least in the "Eulemur fulvus group". In fact, several Eulemur species also form viable hybrid populations in some areas in Madagascar [52, 53], even among species exhibiting strong acoustic differences in their loud calls. Acoustic signals seem therefore not be used for avoidance of heterospecific mating in eulemurs, and it seems rather unlikely that call diversification evolved via sexual selection.

\section{Species recognition and natural selection}

Differences between loud calls of the "Eulemur fulvus group" seem not to be strong enough that E. rufifrons showed differentiated responses after presentation of their own loud calls and those of closely related species. Natural selection and habitat differences therefore seem unlikely to be responsible for the divergence of acoustic signals in eulemurs. There are several Eulemur species 
occurring in similar habitats along the east coast as well as along the west coast (see [45]). Acoustic differences are not stronger between eastern and western species than between species occurring only in the east or only in the west [44]. And, there is also no difference between loud calls of the eastern and the western E. rufifrons populations [44] although the same species occurs in different habitats with different ecologies [54]. Moreover, Eulemur species occurring in sympatry show the strongest acoustic differences in loud calls despite inhabiting the same habitat and being exposed to similar natural selection pressures [44]. This effect is also evident in our study species because $E$. rufifrons and $E$. rubriventer in RNP show strong acoustic differences. Therefore, natural selection and habitat differences seem unlikely to have played a role in the diversification of acoustic signals in E. rufifrons.

\section{Species recognition and genetic drift}

Finally, it is likely that the observed call divergence is mostly influenced by genetic drift. The fact that differences between loud calls of closely related eulemurs are rather small and calls get more distinctive as genetic distance between taxa increases [44], suggests an influence of genetic drift. Although our sample size is rather small, the acoustic and genetic distances correlated positively among the Eulemur species investigated in this study. $E$. rufifrons in both populations did not distinguish between calls of closely related species. Since closely related Eulemur taxa diverged more recently, genetic drift might not have yet produced strong differences between loud calls to be recognized. In contrast, a recent playback study on two subspecies of saddle-back tamarins (Saguinus fuscicollis nigrifrons and $S$. $f$. lagonotus) revealed that Saguinus fuscicollis nigrifrons differentiated between long calls of these two subspecies [55]. However, divergence estimates for these taxa are about 2.9 million years [56], whereas taxa from the "Eulemur fulvus group" diverged only during the last 1 million years [44]. Interestingly, in the KF populations, the time spent looking towards the speaker correlated negatively with the genetic distance to the stimulus species, indicating potential effects of genetic drift. Therefore, it seems most parsimonious to conclude at this point that genetic drift played a major role in the diversification of acoustic signals in eulemurs.

\section{Potential mechanisms involved in species recognition}

Acoustic recognition of heterospecific calls has also been documented in other species of mammals occurring in sympatry, for example between redfronted lemurs and Verreaux's sifakas (Propithecus verreauxi) [57], between ring-tailed lemurs (Lemur catta) and P. verreauxi [58] and between bonnet macaques (Macaca radiata) and two species of langurs (Trachypithecus johnii and Semnopithecus entellus) and Sambar deer [59]. Those studies underline the importance of experience and learning for the ability to recognize heterospecific calls for sympatric species and might explain why E. rufifrons in this study responded more strongly to loud calls of sympatric $E$. rubriventer in RNP than in KF. Therefore, our results suggest that in $E$. rufifrons in RNP learning may play a role in recognizing heterospecific calls. As E. rufifrons and E. rubriventer occur sympatrically at RNP, E. rufifrons might have paid more attention to loud calls of E. rubriventer because they indicate the presence of a food competitor [60, 61]. In fact, experiments were conducted mostly during guava fruiting season and animals of both species were observed feeding from the same resources (personal obs., see also [61]). It is also known that in some species of primates territorial confrontations may occur with neighboring groups of different species and that vocal signals such as loud calls may be used in such contexts in order to defend mates or resources (e.g. between saddle-back tamarins (Saguinus fuscicollis avilapiresi) and red-capped moustached tamarins (Saguinus mystax pileatus) [62]).

\section{Other signals for species recognition in eulemurs}

Primates and other animals use different signals for communication, and the use of species-specific signals for species recognition has already been demonstrated by several authors $[6,10,11,14,23-25]$. However, only few studies have investigated the role of species-specific signals in lemurs [22, 43], even though they represent endpoints of recent adaptive radiations. Whereas species recognition based on olfactory cues has been demonstrated in true lemurs (Eulemur sp. [23]) only one study analyzed the role of visual species-specific signals (facial features) in eulemurs [28]. Our study tested the ability of redfronted lemurs to recognize conspecifics from heterospecifics via acoustic signals, suggesting that acoustic signals apparently play a less important role for eulemurs in species recognition. However, Eulemur species exhibit a wide variety in terms of facial color patterns and especially males, with the exception of E. rufifrons and E. rufus (see [45, 63]), show colorful and pronounced facial hair patterns that could serve as speciesspecific visual signals. We therefore suggest that future studies on species recognition using visual signals may provide important insights into the relative importance of either olfactory, acoustic or visual signals in species recognition of eulemurs.

\section{Conclusions}

We conclude that E. rufifrons are not able to discriminate between loud calls of closely related species living in allopatry and that responses to more distantly related congeners are likely to be modulated by experience. E. rufifrons at KF discriminated between loud calls of them and their own 
calls, whereas E. rufifrons at RNP did not. Because members of the two study populations responded differently to these calls, we suggest that experience, presumably based on learning, may have modulated the response of the RNP population to calls of E. rubriventer, which acts as a food competitor there. In addition, species differences in loud calls are likely partly the result of genetic drift. Since closely related Eulemur taxa diverged only recently, genetic drift might not have yet produced strong differences between loud calls to be recognized, suggesting that these calls are less important for species recognition in these cathemeral primates. Thus, playback experiments are important to understand whether differences between acoustic signals used for species delimitation are also used by the animals themselves to discriminate between conspecific and heterospecific calls.

\section{Methods}

\section{Study sites}

Playback experiments were conducted at two sites in Madagascar: Kirindy Forest (KF) and Ranomafana National Park (RNP) (Fig. 4). At KF, Eulemur rufifrons have been individually marked as part of a long-term study [64, 65], and we studied 16 individuals (eight females and eight males) from four groups. At RNP, we studied 21 individuals (11 females and ten males) from seven groups that were distinguished by their size, sex ratio and home range location. We recognized individuals through earmarks, scratches or distinctive fur coloration.

\section{Playback stimuli and design}

Loud calls (croaks) used as playback stimuli were recorded as responses to playback experiments with conspecific loud calls in wild populations of E. albifrons, E. fulvus, E. rubriventer, E. rufifrons and $E$. rufus as part of an earlier study ([44], Fig. 5, see also Additional files 1, 2, 3, 4, 5). Recordings were made with a Marantz solid-state recorder PMD 660 (frequency response 40-20.000 Hz) and a Sennheiser directional microphone K6 power module and ME66 recording head (frequency response $40-20.000 \mathrm{~Hz}$ ) with a MZ W66 pro windscreen. Because E. rufifrons usually produces bouts of loud calls in territorial contexts, each playback stimulus was repeated twice with intervals of $5 \mathrm{~s}$ silence in between, using Cool Edit 2000 (Syntrillium Phoenix, AZ). The sound pressure level of all playback stimuli was adjusted to $34 \pm 3 \mathrm{~dB}$ using Cool Edit and broadcast with the same volume settings at the loud speaker. Playback stimuli were presented with a Marantz solid-state recorder PMD 660 connected to a loud speaker (Davidactve, Visonik) hidden in the vegetation at a distance of $10 \mathrm{~m}$ behind a focal animal, so that the individual looking towards the speaker had to look in the opposite direction of the researcher, who was

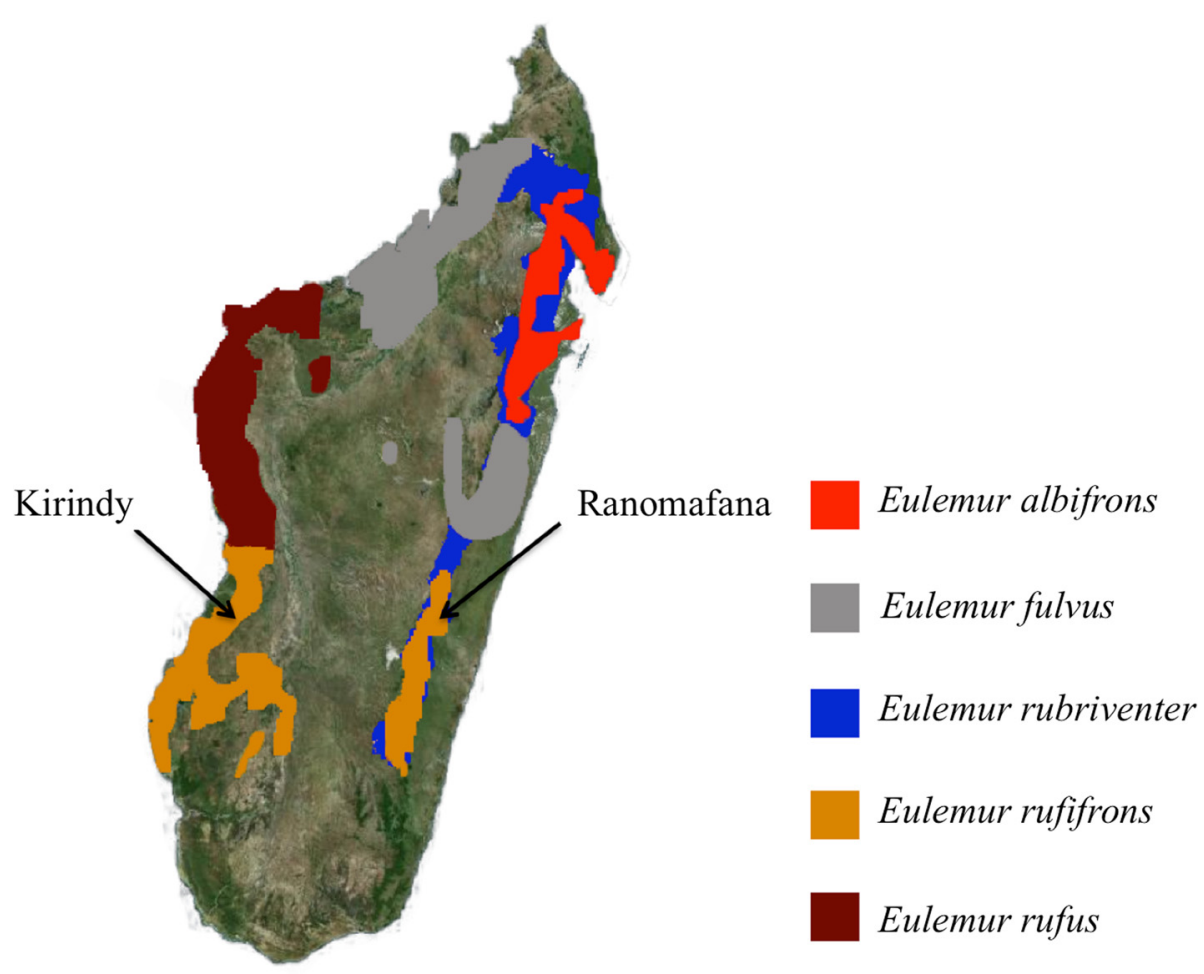

Fig. 4 Map of Madagascar with distribution of Eulemur species used as stimuli for playback experiments and locations of field sites 


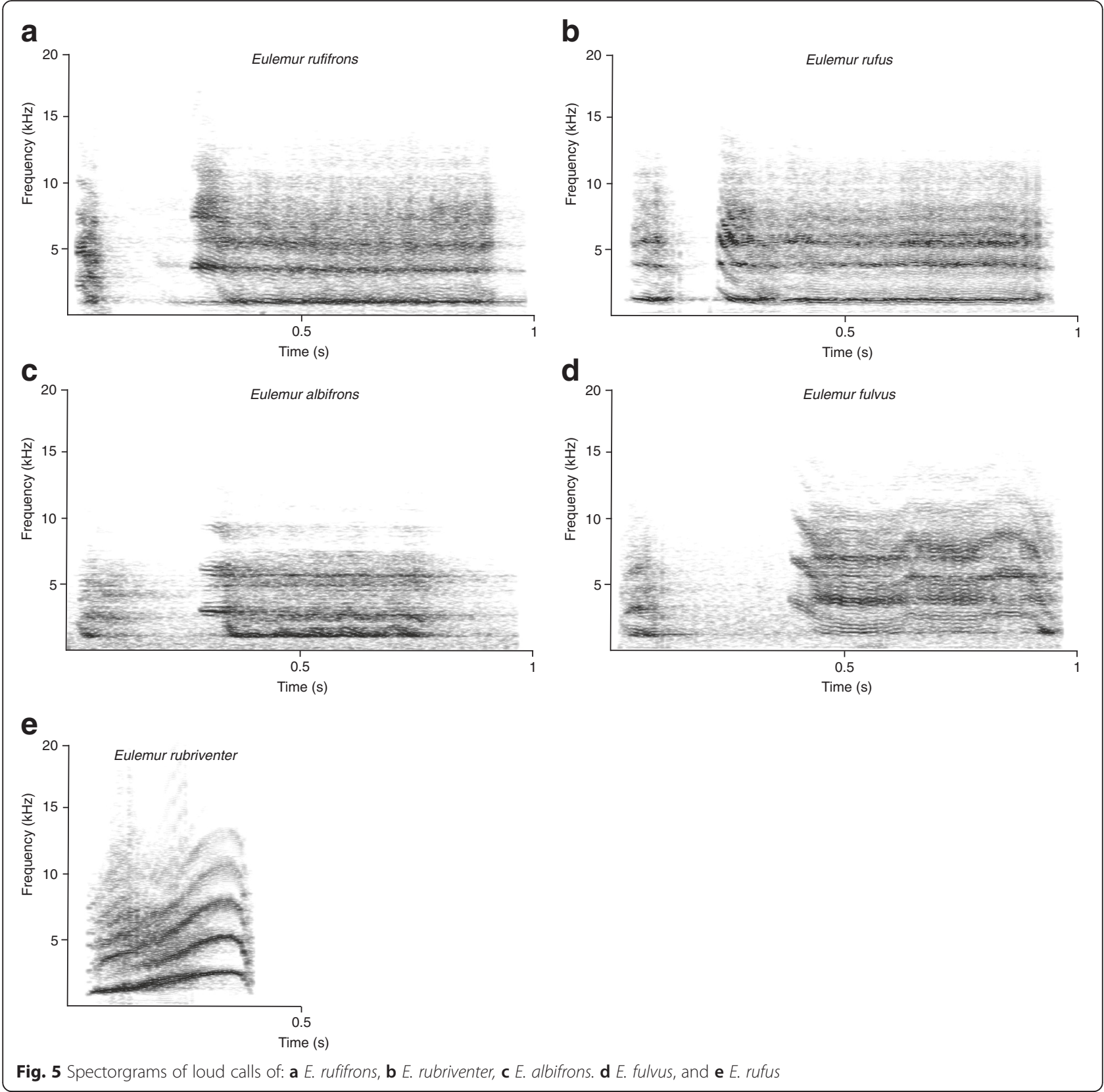

positioned at a distance of about $7 \mathrm{~m}$ in front of the focal subject to video-tape its response.

We used the following 5 stimuli for playback experiments in the KF population: loud calls of E. albifrons, E. fulvus, E. rubriventer, E. rufifrons and E. rufus (Fig. 5, Table 2). In the RNP population, the number of playback stimuli was reduced from 5 to 3 because some of the groups at RNP could not be located on a regular basis. We therefore presented E. rufifrons at RNP only loud calls of their own species as well as calls of $E$. albifrons and E. rubriventer (Table 2). In both populations, we used as heterospecific playback stimuli the same calls, however, as conspecific playback stimulus we used

Table 2 Number of individuals tested for each playback stimulus in both populations

\begin{tabular}{lll}
\hline & \multicolumn{2}{l}{ Population } \\
\cline { 2 - 3 } Species of playback stimulus & Kirindy Forest & Ranomafana National Park \\
\hline Eulemur rufifrons & $N=16$ & $N=16$ \\
Eulemur albifrons & $N=16$ & $N=17$ \\
Eulemur rubriventer & $N=16$ & $N=17$ \\
Eulemur fulvus & $N=16$ & \\
Eulemur rufus & $N=16$ & \\
\hline
\end{tabular}


calls that were recorded in the respective population (Kirindy or Ranomafana). Since in earlier playback studies with subjects from the population in Kirindy Forest focal subjects did not respond to controls (loud calls from chacma baboons or the song from a local parrot $[47,57])$, we refrained from using such a control in the current study because of the low response and the logistical efforts for every single playback are enormous - especially in the rain forest.

Playbacks were conducted only with animals that were engaged in relatively quiet activities, such as resting or grooming. To avoid pseudo-replication, we used loud calls from a different individual for each playback experiment, and subjects were tested with each stimulus in a randomized but counter-balanced order. Each playback stimulus was tested only once every $2^{\text {nd }}$ day per group. Subjects' responses to the playback stimuli were recorded with a SONY digital video camera briefly before and $1 \mathrm{~min}$ after the onset of each playback experiment. Based on these video-recordings we measured the time the animal spent looking towards the speaker (looking direction within $45^{\circ}$ angle to the direct line of sight towards the loud speaker, see Additional file 6) and time spent looking around in other directions after the onset of the playback stimulus, and we calculated the percentage of time spent looking towards the speaker from the total time spent looking around. Video analyses were conducted with a frame-by-frame analysis with a resolution of 30 frames/s using Adobe Premiere Elements (12.0). 10 \% of all experiments were scored by a second observer, naive to the research question. The Interclass Correlation Coefficient was very good with $\mathrm{ICC}=0.97$.

\section{Statistic analyses}

Linear mixed models (LMM) were used to test for differences in the percentage of time spent looking towards the speaker of redfronted lemurs in response to different playback stimuli in both populations respectively using lmerTest package in $\mathrm{R}$ [66]. Percentage of time spent looking towards the speaker was arcsine-squareroot transformed and fitted as response. Playback stimulus and sex were fitted as fixed factors and individual identity as random factor. LMMs were also used to examine whether genetic distances between species influenced the percentage of time spent looking towards the speaker, with the latter variable fitted as response, genetic distance and sex as fixed factors and individual identity as random factor. To test for differences in responses of E. rufifrons to loud calls of E. albifrons, E. rubriventer and E. rufifrons between the two populations (KF and RNP), we conducted a Mann-Whitney $U$ test.

To examine the relationship between genetic distance and acoustic signal divergence, we calculated the Euclidian distance between each pair of species on the basis of the group centroids revealed by a discriminant function analysis calculated in SPSS [44]. The function cophenetic.phylo of the R package APE 3.0-11 was used to calculate pairwise genetic distances between pairs of tips from a phylogenetic tree using its branch length, using the Eulemur species tree published by Markolf et al. [44]. Since both populations of $E$. rufifrons do not differ genetically [44], they were combined for this analysis. Acoustic and genetic distances were then subjected to a Spearman's rank correlation. All analyses were conducted in R version 3.1.2.

\section{Ethics approval and consent to participate}

Not applicable.

\section{Consent for publication}

Not applicable.

\section{Availability of data}

The data will be made available in a public database (dryad.org) prior to publication.

\section{Additional files}

\section{Additional file 1: Audio file of one loud call of Eulemur rufifrons.} (WAV $3750 \mathrm{~kb}$ )

Additional file 2: Audio file of one loud call of Eulemur rufus. (WAV 3730 kb)

Additional file 3: Audio file of one loud call of Eulemur albifrons. (WAV 3746 kb)

Additional file 4: Audio file of one loud call of Eulemur fulvus. (WAV $3744 \mathrm{~kb}$ )

Additional file 5: Audio file of one loud call of Eulemur rubriventer. (WAV 3636 kb)

Additional file 6: Average looking duration towards the speaker after each playback stimulus in the populations at Kirindy Forest and Ranomafana National Park. (PDF $110 \mathrm{~kb}$ )

Competing interests

The authors declare that they have no competing interests.

Authors' contributions

HR, PMK, CF conceived the study and wrote the manuscript. HR collected the data. HR, CF analyzed the data. All authors read and approved the final manuscript.

\section{Acknowledgements}

We thank the Malagasy Ministère de l'Environnement et des Eaux et Forêts, the Departement de Biologie Ecologie et Conservation Animale de l'Université d'Antananarivo, the Centre National de Formation, d'Etudes et de Recherche en Environnement et Foresterie de Morondava, Madagascar National Parks and the Centre ValBio Ranomafana for allowing and supporting research in Kirindy Forest and Ranomafana National Park. We are grateful to our field assistants Tiana, Jipa, Mamy and Victor without whom playback experiments would not have been possible. The clarity of a previous version of this manuscript was greatly improved by comments from two anonymous referees, whom we also wish to thank.

Funding

This study was financially supported by the German Primate Center in Göttingen Germany and the German Academic Exchange Service (DAAD). 


\section{Author details}

'Behavioral Ecology \& Sociobiology Unit, German Primate Center, Göttingen, Germany. ${ }^{2}$ Department of Sociobiology/Anthropology, University of Göttingen, Göttingen, Germany.

\section{Received: 16 January 2016 Accepted: 3 May 2016}

Published online: 12 May 2016

\section{References}

1. Ryan MJ, Rand AS. Species recognition and sexual selection as a unitary problem in animal communication. Evolution. 1993:47:647-57.

2. Grant PR, Grant BR. Species before speciation is complete. Ann Mo Bot Gard. 2006;93:94-102.

3. Robillard T, Höbel G, Gerhardt HC. Evolution of advertisement signals in North American hylid frogs: vocalizations as end-products of calling behavior. Cladistics. 2006;22:533-45.

4. Gray D, Cade WH. Sexual selection and speciation in field crickets. Proc Natl Acad Sci U S A. 2000:97:14449-54.

5. Coyne JA. Genetics and speciation. Nature. 1992;355:511-5.

6. Höbel G, Gerhardt HC. Reproductive character displacement in the acoustic communication system of green tree frogs (Hyla cinerea). Evolution. 2003;57: 894-904.

7. Kraaijeveld K, Kraaijeveld-Smit FJL, Maan ME. Sexual selection and speciation: the comparative evidence revisited. Biol Rev. 2011:86:367-77.

8. Mayr E. What is a species, and what is not? Philos Sci. 1996;63:262-77.

9. Nevo E, Heth G, Beiles A, Frankenberg E. Geographic dialects in blind mole rats: Role of vocal communication in active speciation. Proc Natl Acad Sci U S A. 1987;84:3312-5

10. Caspers BA, Schroeder FC, Franke S, Streich WJ, Voigt CC. Odour-based species recognition in two sympatric species of sac-winged bats (Saccopterix bilineata, S. leptura): combining chemical analyses, behavioural observations and odour preference tests. Behav Ecol Sociobiol. 2009:63:741-9.

11. McLennan DA, Ryan MJ. Responses to conspecific and heterospecific olfactory cues in the swordtail Xiphophorus cortezi. Anim Behav. 1997;54:1077-88.

12. Seehausen O, Terai Y, Magalhaes IS, Carleton KL, Mrosso HDJ, Miyagi R, et al. Speciation through sensory drive in cichlid fish. Behav Ecol Sociobiol. 2008;42:1-8.

13. Boul KE, Funk WC, Darst CR, Cannatella DC, Ryan MJ. Sexual selection drives speciation in an Amazonian frog. Proc R Soc Lond B. 2007;274:399-406.

14. Curé C, Mathevon N, Mundry R, Aubin T. Acoustic cues used for species recognition can differ between sexes and sibling species: evidence in shearwaters. Anim Behav. 2012;84:239-50.

15. Raemaekers JJ, Raemaekers PM. Field playback of loud calls to gibbons (Hylobates lar): territorial, sex-specific and species-specific responses. Anim Behav. 1985;33:481-91.

16. Feng AS, Narins PM, Xu C-H, Lin W-Y, Yu Z-L, Qiu Q, et al. Ultrasonic communication in frogs. Nature. 2006;440:333-6.

17. Slabbekoorn H, Smith TB. Habitat-dependent song divergence in the little greenbul: an analysis of environmental selection pressures on acoustic signals. Evolution. 2002;56:1849-58.

18. Grant PR, Grant BR. The secondary contact phase of allopatric speciation in Darwin's finches. Proc Natl Acad Sci U S A. 2009;106:20141-8.

19. Campbell P, Pasch B, Pino JL, Crino OL, Phillips M, Phelps SM. Geographical variation in the songs of neotropical singing mice: testing the relative importance of drift and local adaptation. Evolution. 2010;64:1955-72.

20. Irwin DE, Thimgan MP, Irwin JH. Call divergence is correlated with geographic and genetic distance in greenish warblers (Phylloscopus trochiloides): a strong role for stochasticity in signal evolution? J Evol Biol. 2008;21:435-48.

21. Kappeler PM. The transmission and function of chemical signals in Lemur catta. Behav Ecol Sociobiol. 1998;42:411-21.

22. delBarco-Trillo J, Sacha CR, Dubay GR, Drea CM. Eulemur, me lemur: the evolution of scent-signal complexity in a primate clade. Philos Trans R Soc B. 2012;367:1909-22.

23. Harrington JE. Responses of Lemur fulvus to scents of different subspecies of L. fulvus and to scents of different species of Lemuriformes. Z Tierpsychol. 1979:49:1-9.

24. Clark AB. Interspecific differences and discrimination of auditory and olfactory signals of Galago crassicaudatus and Galago garnettii. Int J Primatol. 1988;9:557-71.

25. Ueno Y. Olfactory discrimination of urine odors from five species by tufted capuchin (Cebus apella). Primates. 1994;35:311-23.
26. Fujita K. Species recognition by five macaque monkeys. Primates. 1987; 28:353-66.

27. Fujita K, Watanabe K, Widarto TH, Suryobroto B. Discrimination of macaques by macaques: the case of Sulawesi species. Primates. 1997:38:233-45.

28. Marechal L, Genty E, Roeder JJ. Recognition of faces of known individuals in two lemur species (Eulemur fulvus and E. macaco). Anim Behav. 2010;79:1157-63.

29. Santana SE, Alfaro JL, Alfaro ME. Adaptive evolution of facial colour patterns in neotropical primates. Proc R Soc B. 2012;279:2204-11.

30. Santana SE, Alfaro JL, Noonan A, Alfaro ME. Adaptive response to sociality and ecology drives the diversification of facial colour patterns in catarrhines. Nat Commun. 2013:4:1-7.

31. Snowdon $C T$, Hodun A, Rosenberger AL, Coimbra-Filho AF. Long-call structure and its relation to taxonomy in lion tamarins. Am J Primatol. 1986;11:253-61

32. Konrad R, Geissmann T. Vocal diversity and taxonomy of Nomascus in Cambodia. Int J Primatol. 2006;27:713-45.

33. Macedonia JM, Stanger KF. Phylogeny of the Lemuridae revisited: evidence from communication signals. Folia Primatol. 1994;63:1-43.

34. Thinh VN, Hallam C, Roos C, Hammerschmidt K. Concordance between vocal and genetic diversity in crested gibbons. BMC Evol Biol. 2011;11:36.

35. Meyer D, Hodges JK, Rinaldi D, Wijaya A, Roos C, Hammerschmidt K. Acoustic structure of male loud calls support molecular phylogeny of Sumatran and Javanese leaf monkeys (genus Presbytis). BMC Evol Biol. 2011;12:16.

36. Fichtel C. Acoustic differences in loud calls of Decken's and crowned Sifakas (Propithecus deckenii and P. coronatus) at two sites in Madagascar. Primate Conservation. 2014;28:85-91.

37. Gamba M, Giacoma C. Subspecific Divergence in the black lemur's low-pitched vocalizations. Open Acoust J. 2008;1:49-53.

38. Brown $\mathrm{CH}$, Gomez R, Waser PM. Old World monkey vocalizations: adaptation to the local habitat? Anim Behav. 1995:50:945-61.

39. Mitani JC. Sexual selection and adult male orangutan long calls. Anim Behav. 1985:33:272-83.

40. Nietsch A, Kopp M-L. Role of vocalization in species differentiation of Sulawesi tarsiers. Folia Primatol. 1998:69:371-8.

41. Muroyama $Y$, Thierry B. Species differences of male loud calls and their perception in Sulawesi macaques. Primates. 1998:39:115-26.

42. Mitani JC. Species discrimination of male song in gibbons. Am J Primatol. 1987;13:413-23.

43. Braune P, Schmidt S, Zimmermann E. Acoustic divergence in the communication of cryptic of nocturnal primates (Microcebus spp.). BMC Biol. 2008:6:19.

44. Markolf M, Rakotonirina H, Fichtel C, Grumbkow P, Brameier M, Kappeler PM. True lemurs... true species - Species delimitation using multiple data sources in the brown lemur complex. BMC Evol Biol. 2013;13:233.

45. Mittermeier RA, Louis Jr EE, Richardson M, Schwitzer C, Langrand O, Rylands A, et al. Lemurs of Madagascar. 3rd ed. Arlington: Conservation International; 2010.

46. Pereira ME, Kappeler PM. Divergent systems of agonistic behaviour in lemurid primates. Behaviour. 1997:134:225-74.

47. Fichtel C, Kappeler PM. Anti-predator behavior of group-living Malagasy primates: mixed evidence for a referential alarm call system. Behav Ecol Sociobiol. 2002;51:262-75.

48. Trivers RL. Parental investment and sexual selection. In: Sexual Selection \& the Descent of Man. New York: Aldine de Gruyter; 1972. p. 136-79.

49. Clutton-Brock TH, Parker GA. Potential reproductive rates and the operation of sexual selection. Q Rev Biol. 1992;67:437-56.

50. Funk WC, Caminer M, Ron SR. High levels of cryptic species diversity uncovered in Amazonian frogs. Proc. R. Soc. Lond. B: Biological Sciences. 2011; 279:1806-14.

51. Kappeler PM. Mate choice. In: The evolution of primate societies. 2012. p. 343-66.

52. Johnson SE. Evolutionary divergence in the brown lemur species complex. In: Gould L, Sauther ML, editors. Lemurs: Ecology and adaptation. New York: Springer; 2007. p. 187-210.

53. Pastorini J, Zaramody A, Curtis DJ, Nievergelt CM, Mundy NI. Genetic analysis of hybridization and introgression between wild mongoose and brown lemurs. BMC Evol Biol. 2009;9:1-13.

54. Muldoon KM, Goodman SM. Ecological biogeography of Malagasy non-volant mammals: community structure is correlated with habitat. J Biogeogr. 2010:37:1144-59.

55. Bradley CE, McClung MR. Vocal divergence and discrimination of long calls in tamarins: A comparison of allopatric populations of Saguinus fuscicollis nigrifrons and S. f. lagonotus. Am J Primatol. 2015;77:679-87. 
56. Matauschek C, Roos C, Heymann EW. Mitochondrial phylogeny of tamarins (Saguinus, Hoffmannsegg 1807) with taxonomic and biogeographic implications for the S. nigricollis species group. Am J Phys Anthropol. 2011;144:564-74.

57. Fichtel C. Reciprocal recognition of sifaka (Propithecus verreauxi verreauxi) and redfronted lemur (Eulemur fulvus rufus) alarm calls. Anim Cogn. 2004;7:45-52

58. Oda R, Masataka N. Interspecific responses of ringtailed lemurs to playback of antipredator alarm calls given by Verreaux's sifakas. Ethology. 1996;102:441-53.

59. Ramakrishnan U, Coss RG. Recognition of heterospecific alarm vocalization by Bonnet macaques (Macaca radiata). J Comp Psychol. 2000;114:3.

60. Overdorff DJ. Similarities, differences, and seasonal patterns in the diets of Eulemur rubriventer and Eulemur fulvus rufus in the Ranomafana National Park, Madagascar. Int J Primatol. 1993;14:721-53.

61. Overdorff DJ, Tecot SR. Social pair-bonding and resource defense in wild red-bellied lemurs (Eulemur rubriventer). In: Gould L, Sauther ML, editors. Lemurs: Ecology and adaptation. New York: Springer; 2007. p. 235-54.

62. Peres CA. Consequences of joint-territoriality in a mixed-species group of tamarin monkeys. Behaviour. 1992;123:220-46.

63. Clough D, Heistermann M, Kappeler PM. Individual facial coloration in male Eulemur fulvus rufus: a condition-dependent ornament? Int J Primatol. 2009;30:859-75

64. Kappeler PM, Fichtel C. A 15-year perspective on the social organization and life history of sifaka in Kirindy Forest. In: Kappeler PM, Watts DP, editors. Longterm field studies of primates. Berlin Heidelberg: Springer; 2012. p. 101-21.

65. Kappeler PM, Fichtel C. Female reproductive competition in Eulemur rufifrons: eviction and reproductive restraint in a plurally breeding Malagasy primates. Mol Ecol. 2012;23:685-98.

66. Kuznetsova A, Brockhoff PB, Christensen RHB. LmerTest: tests for random and fixed effects for linear mixed effect models. R package Version 2.0-3. 2013, http://CRAN.R-project.org/packageplmerTest.

\section{Submit your next manuscript to BioMed Central and we will help you at every step:}

- We accept pre-submission inquiries

- Our selector tool helps you to find the most relevant journal

- We provide round the clock customer support

- Convenient online submission

- Thorough peer review

- Inclusion in PubMed and all major indexing services

- Maximum visibility for your research

Submit your manuscript at www.biomedcentral.com/submit 